\title{
Unilateral and bilateral ECT: a study of memory disturbance and relief from depression
}

\author{
D. CRONin, P. BODley, L. POTTS ${ }^{1}$, MARCiA D. MATHER, R. K. GARDNER, \\ AND JEAN C. TOBIN \\ From Warley Hospital, Brentwood, Essex
}

SUMMARY Fifty-one endogenous and reactive female depressives were given a course of either unilateral non-dominant, unilateral dominant, or bilateral ECT. Visual and verbal memory tests and confusion ratings were administered at frequent intervals during the treatment course. Preand post-treatment assessments of depression were made. Comparisons of the therapeutic effect of six and of eight ECTs were studied separately. One month after the last ECT the patients were again assessed on the memory and the depression tests. The results of the memory tests indicate that unilateral non-dominant ECT produced least memory disturbance (particularly of a verbal kind) and also less immediate confusion within 40 minutes of each ECT. This observation applies more to the reactive than the endogenous group. Comparisons of the depression tests reveal that unilateral non-dominant ECT is as effective in relieving depression as bilateral ECT, though progress may be less rapid. The observation holds true only for the reactive depressives. Endogenous depressives benefit more from bilateral ECT. Caution is advised against the administration of unilateral dominant ECT, since this group does not respond to treatment as well as the other two groups. Degree of improvement as a whole does not appear to be related to the degree of confusion experienced. The implications of these findings are discussed.

There have been a number of studies recently reporting the relative benefits of unilateral and bilateral electro-convulsive therapy (ECT) in terms of posttreatment memory loss and recovery from depression. Many reports have included surveys and criticisms of the literature on the subject, therefore it is not intended to consider in any detail the development or background of the treatment, but to summarize briefly the conclusions.

1. There is general agreement that ECT applied unilaterally to the non-dominant cerebral hemisphere (unilateral non-dominant ECT) produces less general memory impairment than bilateral ECT (Lancaster, Steinert, and Frost, 1958; Cannicott, 1962; Martin, Ford, McDonald, and Towler, 1965; Impastato and Karliner, 1966; Levy, 1968; Zinkin and Birtchnell, 1968).

2. The kind of memory and cognitive impairment shown after unilateral ECT is related to the side of the electrode placement-that is, on the dominant or non-dominant hemisphere. There is more verbal

'Present address: Highland Hospital, Department of Psychiatry, Ashville, North Carolina, U.S.A. deficit after unilateral dominant ECT (Gottlieb and Wilson, 1965; Zamora and Kaelbling, 1965; Halliday et al., 1968), while visual functions are affected by unilateral non-dominant ECT (Halliday, Davison, Browne, and Kreeger, 1968).

3. There is less agreement about the effect of unilateral non-dominant ECT on depression. Some studies have reported less improvement after unilateral non-dominant treatment than bilateral treatment (Pacella and Impastato, 1954; Lancaster et al., 1958; Impastato and Karliner, 1966), while others show no significant difference in therapeutic effect of the two treatments (Cannicott, 1962; Martin et al., 1965; Levy, 1968; Zinkin and Birtchnell, 1968). Halliday et al. (1968) suggest that unilateral non-dominant ECT is as effective as bilateral ECT, although more treatments may be needed.

4. There is some difference of opinion about the effect of unilateral dominant ECT on depressive symptoms. Halliday et al. (1968) noted a considerable drop-out rate among patients receiving unilateral dominant ECT, suggesting that they may have deteriorated. However, McAndrew, Berkey, 
and Matthews (1967), who also compared both kinds of unilateral with bilateral ECT, found no differences in improvement rate.

The present investigation attempts to assess the effects of the three kinds of ECT on memory function and depression. The studies to date are particularly inconclusive regarding the effects of unilateral dominant ECT on depressive symptoms, and only two studies have considered it.

It is hoped that this work will contribute in several other ways. (a) The responses of both reactive and endogenous depressive patients have been investigated separately. ${ }^{1}$ Previous studies have included patients with different kinds of depressive symptoms and different diagnostic categories but have not controlled for these variables. (b) The immediate effects of a course of six treatments have been compared with those of a course of eight treatments. There has been great variability in the literature in the number of treatments administered, and it has been only tentatively suggested that more unilateral treatments are needed to relieve depression. (c) Memory functions were assessed at various stages throughout the course of treatment rather than the usual pre- and post-course assessments.

It is worth noting that at the beginning of the investigation in January 1968, we contacted twelve psychiatric hospitals in S.E. England to ascertain whether or not they were using the unilateral method of treatment. The information obtained was that one hospital was using it; several had tried it and rejected it because it was not as effective as the bilateral method in the treatment of depression; some workers had not tried it at all. One hospital had considerable experience in the treatment method and was using it either on its own or in conjunction with the bilateral method (Dick, 1967). It transpired, therefore, that unilateral ECT was not a commonly used or an accepted form of treatment for depression.

\section{METHOD}

The method used for unilateral treatment was similar to that described by Lancaster et al. (1958) with some exceptions. The patients were given atropine $1.2 \mathrm{mg}$ intravenously immediately before induction. Anaesthesia was then induced with $1 \%$ methohexitone followed by suxamethonium bromide 90 to $120 \mathrm{mg}$. When the muscular twitching had stopped the patients were gently ventilated with oxygen for 45 seconds, the shock administered, and the patients ventilated until spontaneous breathing was resumed. In order not to invalidate testing the dose of

${ }^{1}$ Note: The concept of reactive/endogenous depressive groups is again topical, and has recently been reviewed when it was suggested that depressive illnesses are best regarded as a single continuum extending between the traditional neurotic and psychotic stereotypes' (Kendell, 1968). The more traditional form of diagnosis is adopted in this study as it is in general use throughout the hospital and is still recommended by such authorities as Mayer Gross et al. (1969). methohexitone was restricted to $8 \mathrm{mg}$ per stone $(6.4 \mathrm{~kg})$ of body weight. As clinical recovery from this drug is rapid, this was also the dose found to avoid awareness consistently during application of the electrodes and the administration of the electro-shock.

The electrodes were applied to the non-dominant or dominant side of the skull according to the group in which the patient fell by random selection. The lower electrode was placed midway between the lateral angle of the orbit and the external auditory meatus and $1 \frac{1}{2}$ in. above this line. The upper electrode was 3 in. higher than the lower, and at an angle of $70^{\circ}$ to the line. The machine used was Siemens Convulsator 622, an apparatus which gives accurate administration of the milliamperage and the time during which treatment in the form of a continuous pulse sequence is applied. The passage of the current was controlled at $400 \mathrm{ma}$ for 2.5 seconds. A generalized modified convulsion was obtained.

For bilateral treatment the electrodes were positioned over the temples in a position closely approximating to the lower electrode in the unilateral method. The same current and time sequence were used.

\section{HYPOTHESES}

From a study of the literature the following hypotheses were made:

I. In terms of memory.

i. That a group having ECT with unilateral non dominant electrode placement would show less impair-a ment on tests of verbal memory than either bilateral or unilateral dominant groups.

ii. That a unilateral dominant group would show less visual memory impairment than a bilateral and a unilateral non-dominant group.

iii. That both unilateral groups would suffer less than would the bilateral group in terms of confusion following individual treatments.

\section{In terms of depression}

i. That both unilateral groups would show less improvement in depression than the bilateral group when a standard number of six ECTs is administered.

ii. That extra treatments would be required by both unilateral groups to obtain the same degree of improvement in depression as the bilateral group.

iii. That for all groups the amount of confusion following each treatment in a standard number of ECTs would be related to degree of improvement in depression.

III. In terms of differences between reactive and endogenous depressive groups.

i. That no differences in memory impairment would be expected between reactive and endogenous groups.

ii. That in terms of depression an endogenous group would improve more than a reactive group on both kinds of ECT.

\section{DESIGN OF INVESTIGATION}

A group of 51 depressives who were consecutive admissions was selected for the study and each allotted to one of two groups according to whether they were of an 
enclogenous or reactive type. All patients were women of age-range 21 to 69 years who had not had ECT for at least three months before the present treatment. The presence of psychiatric symptoms other than depression or of organic signs (whether found by the psychiatrist or psychologist on testing) excluded a patient from the trial.

Diagnosis of the type of depression was determined by means of an item check list which discriminated between the two distinct depressive syndromes. This was based on a study by Carney, Roth, and Garside (1965) who showed by principal component analysis that a bipolar factor accounted for a greater part of the variance than a general factor of depression. Thus, in the present study, the patients were observed clinically by the psychiatrist and appropriate symptoms checked off the list. The assignment of a patient to the endogenous or reactive group was determined by the optimal discriminatory cut-off point.

The two groups of depressives (reactive and endogenous) were each subdivided into three groups, those receiving bilateral ECT, those receiving unilateral ECT to the dominant hemisphere, and those receiving unilateral ECT to the non-dominant hemisphere (Table 1).

Both right- and left-handed patients were originally

TABLE 1

DIVISION OF GROUPS*

\begin{tabular}{lcc}
\hline & $\begin{array}{c}\text { Reactive } \\
\text { depressives }\end{array}$ & $\begin{array}{c}\text { Endogenous } \\
\text { depressives }\end{array}$ \\
\hline $\begin{array}{l}\text { Non-dominant } \\
\text { unilateral ECT }\end{array}$ & 9 & 7 \\
$\begin{array}{l}\text { Bilateral ECT } \\
\begin{array}{l}\text { Dominant } \\
\text { unilateral ECT }\end{array}\end{array}$ & 8 & 7 \\
\hline
\end{tabular}

*At follow-up there was one less patient in each reactive group, owing to failure to keep appointment. included in the design, although there is some indication (Williams, 1965) that left-handers may not have a dominant hemisphere and that they may be ambidextrous. Nonetheless they were included in the trial for practical and interest purposes, but this group proved too small for separate analysis and was ultimately omitted altogether. This brought the total number in the analysis to 45 .

Eight treatments were given to each patient at the rate of two treatments weekly. Two treatments in addition to the usual six ECTs were given in order to assess hypothesis II (ii) as above. The psychologists administering the tests and assessing the patients did not know what kind of ECT each was receiving until after the trial was completed.

Assessments of memory (both visual and auditory), severity of depression, and the presence of delusional guilt were made by the psychologists before treatment and at intervals during and after treatment (Table 2). Questions relating to the presence of confusion and ratings of restlessness (which can be obtained from the authors on request) were also administered by the nursing staff at five-minute intervals after each individual ECT until 40 minutes after the ECT.

Both immediate memory function and the long-term effects of ECT on memory were assessed, since it has been suggested that the subjective feeling of improvement was related to immediate reproduction scores rather than to long-term retention-that is, after more than three hours (hypothesis II (iii) above). The mean age and mean vocabulary scores (Terman-Merrill Form L) of the six groups are shown in Table 3.

\section{DESCRIPTION AND RATIONALE OF TESTS}

1. Dominance Criteria (Zamora and Kaelbling, 1965).

2. DEPRESSION The Beck Depression Inventory (referred to as the DI), which has been validated both in the U.S.A. and in Great Britain, was considered an appropriate

TABLE 2

ASSESSMENT OF MEMORY, DEPRESSION, AND DELUSIONAL GUILT

\begin{tabular}{|c|c|c|c|}
\hline Testing session & Assessment times & Tests administered & General rationale \\
\hline 1 & $\begin{array}{l}\text { Pre-treatment } \\
\text { ( } 3 \text { days before ECT) }\end{array}$ & Tests of $\left\{\begin{array}{l}\text { memory } \\
\text { depression } \\
\text { dominance }\end{array}\right.$ & Base-line assessment \\
\hline - & $\begin{array}{l}5 \text { min. intervals after } \\
\text { each ECT }\end{array}$ & Ratings of confusion & Immediate memory effects \\
\hline 2 & $1 \mathrm{hr}$ after $1 \mathrm{st} \mathrm{ECT}$ & Tests of memory & $\begin{array}{l}\text { Immediate memory effects using standard } \\
\text { tests }\end{array}$ \\
\hline 3 & $1 \mathrm{hr}$ after 6 th $\mathrm{ECT}$ & Tests of memory & $\begin{array}{l}\text { Immediate memory effects after } 6 \text { ECT } \\
\text { course }\end{array}$ \\
\hline \multirow[t]{2}{*}{4} & \multirow[t]{2}{*}{$24 \mathrm{hr}$ after 6 th $\mathrm{ECT}$} & Tests of memory & $\begin{array}{l}\text { Delayed memory function after } 6 \text { ECT } \\
\text { course }\end{array}$ \\
\hline & & Tests of depression & $\begin{array}{l}\text { Immediate therapeutic effect of } 6 \text { ECT } \\
\text { course }\end{array}$ \\
\hline 5 & $1 \mathrm{hr}$ after $8 \mathrm{th}$ ECT & Tests of memory & $\begin{array}{l}\text { Immediate memory effects after } 8 \mathrm{ECT} \\
\text { course }\end{array}$ \\
\hline \multirow[t]{2}{*}{6} & \multirow[t]{2}{*}{$24 \mathrm{hr}$ after 8th ECT } & Tests of memory & $\begin{array}{l}\text { Delayed memory function after } 8 \mathrm{ECT} \\
\text { course }\end{array}$ \\
\hline & & Tests of depression & $\begin{array}{l}\text { Immediate therapeutic effect of } 8 \mathrm{ECT} \\
\text { course }\end{array}$ \\
\hline 7 & $4 / 6$ weeks after 8 th $\mathrm{ECT}$ & Tests of $\left\{\begin{array}{l}\text { memory } \\
\text { depression }\end{array}\right.$ & $\begin{array}{l}\text { Assessment of memory recovery. Prolonged } \\
\text { therapeutic effect of total ECT course }\end{array}$ \\
\hline
\end{tabular}


TABLE 3

MEAN AGE AND VOCABULARY SCORES OF SIX GROUPS

\begin{tabular}{|c|c|c|c|c|}
\hline & $\begin{array}{c}\text { Mean } \\
\text { age }\end{array}$ & Range & $\begin{array}{c}\text { Mean } \\
\text { vocabulary }\end{array}$ & Range \\
\hline \multicolumn{5}{|l|}{ Reactive } \\
\hline $\begin{array}{l}\text { unilateral non-dominant ECT } \\
\text { bilateral ECT } \\
\text { unilateral dominant ECT }\end{array}$ & $\begin{array}{l}41 \\
52 \\
49\end{array}$ & $\begin{array}{l}21-67 \\
33-65 \\
27-64\end{array}$ & $\begin{array}{l}28 \\
27 \\
24\end{array}$ & $\begin{array}{l}22-41 \\
17-37 \\
17-31\end{array}$ \\
\hline \multicolumn{5}{|l|}{ Endogenous } \\
\hline $\begin{array}{l}\text { unilateral non-dominant ECT } \\
\text { bilateral ECT } \\
\text { unilateral dominant ECT }\end{array}$ & $\begin{array}{l}53 \\
52 \\
55\end{array}$ & $\begin{array}{l}42-67 \\
40-61 \\
24-69\end{array}$ & $\begin{array}{l}23 \\
26 \\
24\end{array}$ & $\begin{array}{l}13-33 \\
16-33 \\
17-31\end{array}$ \\
\hline
\end{tabular}

measure of depth of depression. The Fould's Psychotic Depression Scale (PDS), which has been found to differentiate between neurotically and psychotically depressed women (Foulds, 1960), was used to measure the extent of delusional guilt.

3. vOCABUlaRY Terman-Merrill Form $L$ (as used in the Modified Word-Learning Test) gave some indication of the patient's intellectual and educational level.

4. MEMORY Both verbal and non-verbal memory tests were administered in order to relate the scores on both kinds of tests to treatment on the dominant and nondominant side.

a. Non-verbal tests: Graham-Kendall Memory for Designs Test; the Benton Visual Retention Test.

b. Verbal tests: Modified Word-Learning Test (MWLT) Digit Span; Wechsler Memory Scale (WMS) Form I, Parts I and II.

The Memory for Designs and the Modified Word Learning Test were used to measure visual and verbal memory respectively.

These two tests were repeated throughout the trial on each of the seven testing sessions. Some degree of practice inevitably must have benefited the patients towards the end of testing, although the benefit derived would, no doubt, be related to the degree of memory improvement. Two additional tests (one verbal and one non-verbal) with equivalent forms were incorporated to minimize practice effects. Since no memory tests are available which provide six to seven equivalent forms, the three forms of the Benton Visual Retention Test were sub-divided into six and a preliminary study to ensure their equivalence was carried out.

Six forms of digit span were constructed (modelled on the WAIS) sub-test. The equivalent forms of these two tests were randomized in their administration.

The Wechsler Memory Scale Parts I and II were short assessments of personal information and orientation.

5. RATINGS AND QUESTIONS OF CONFUSION AND RESTLESSNESS These were devised by the psychiatrist to determine rate of recovery after each treatment.

\section{RESULTS}

\section{HYPOTHESIS I}

DIFFERENCES IN MEMORY IMPAIRMENT AND CONFUSION BETWEEN TREATMENT GROUPS The Kruskal-Wallis analysis of variance (Siegel, 1956) was used to assess the significance of the differences between the three treatments, unilateral non-dominant, bilateral, and unilateral dominant ECT on each of the tests for each of the trials separately. For the first analysis the reactive and endogenous groups were combined. The same analysis was then carried out on the reactive and endogenous groups separately. It is acknowledged by the authors that the dichotomous grouping of depressives is controversial and thus combined groups and separate groups were subjected to analysis.

i. Verbal memory The hypothesis that the unilateral nondominant group would show less impairment on tests of verbal memory than either of the other two treatment groups held up on the MWLT. They performed significantly better at follow-up on this test than either of the other two groups $(P<\cdot 01)$. Breaking down the groups into reactive and endogenous depressives, this difference emerged mainly in the reactive group $(<\cdot 05)$; the endogenous groups showed no differences between treatments in terms of verbal memory. No significant differences between treatments were found on any other MWLT sessions. Despite this, Fig. 1 shows that there was a general tendency for the unilateral non-dominant group to perform better. The pre-treatment testing of the reactive group on WMS Part II and Digit Span produced significant differences $(P=\cdot 05$ and $\cdot 02$ respectively). Therefore, these scores were rejected from further analysis. No other significant differences were found for verbal memory. However, Fig. 2 shows that, towards the end of the series of treatments and at follow-up, unilateral non-dominant scores were superior on the WMS Part I (Personal and Current Information).

ii. Visual memory The hypothesis that the unilateral dominant ECT group would show less visual memory impairment than the other groups was rejected. No 


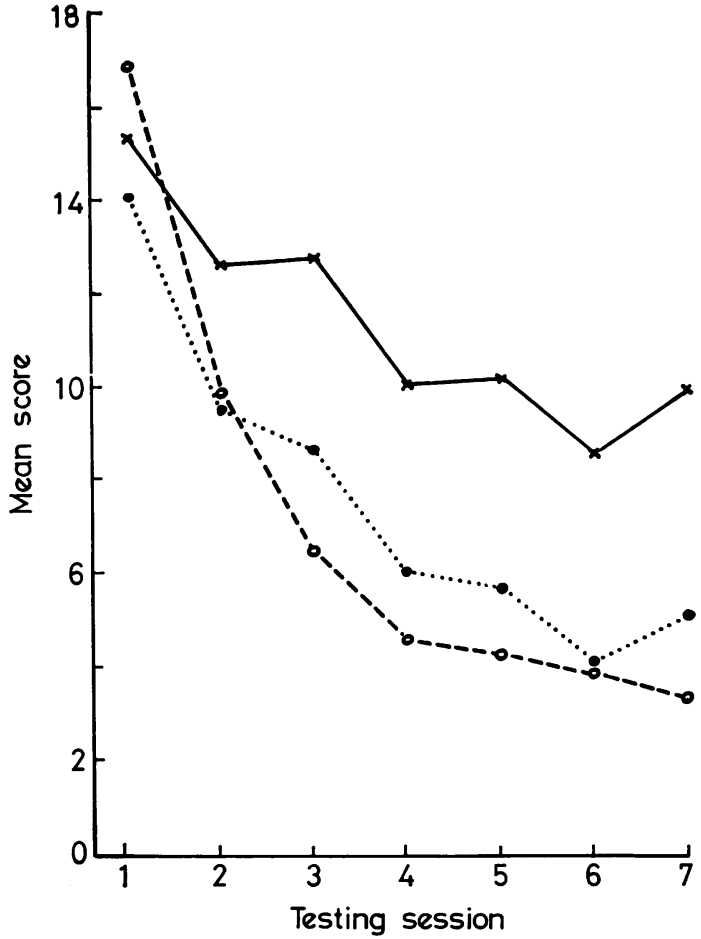

FIG. 1. Mean Modified Word-Learning Test scores for treatment groups. $\mathbf{0}----\mathbf{0}=$ Unilateral non-dominant. $\times \longrightarrow=$ Bilateral. $\bigcirc . . .0=$ Unilateral dominant.

significant differences between the three treatments were found on the visual memory tests for the two depressive groups when analysed either together or separately.

iii. Confusion and restlessness The hypothesis that both unilateral groups would suffer less than the bilaterals in terms of confusion after individual treatments was in part confirmed. On each of eight ratings (one after each ECT) both unilateral groups showed significantly less confusion and restlessness than the bilateral ( $P$ ranging from .02 to $\cdot 001$ ). This can be seen clearly in Fig. 3 . The differences between treatments occurred mainly within the reactive group (Table 4). Only one significant difference was found in the endogenous groups. The mean confusion scores of the endogenous bilateral groups were, however, consistently worse than the unilateral groups.

\section{HYFOTHESIS II}

DIFFERENCES IN DEPRESSION BETWEEN THE TREATMENT GROUPS i. The hypothesis that both unilateral groups would show less improvement in depression than the bilateral group when a standard number of six ECTs is given is not altogether confirmed. Comparison of the DI

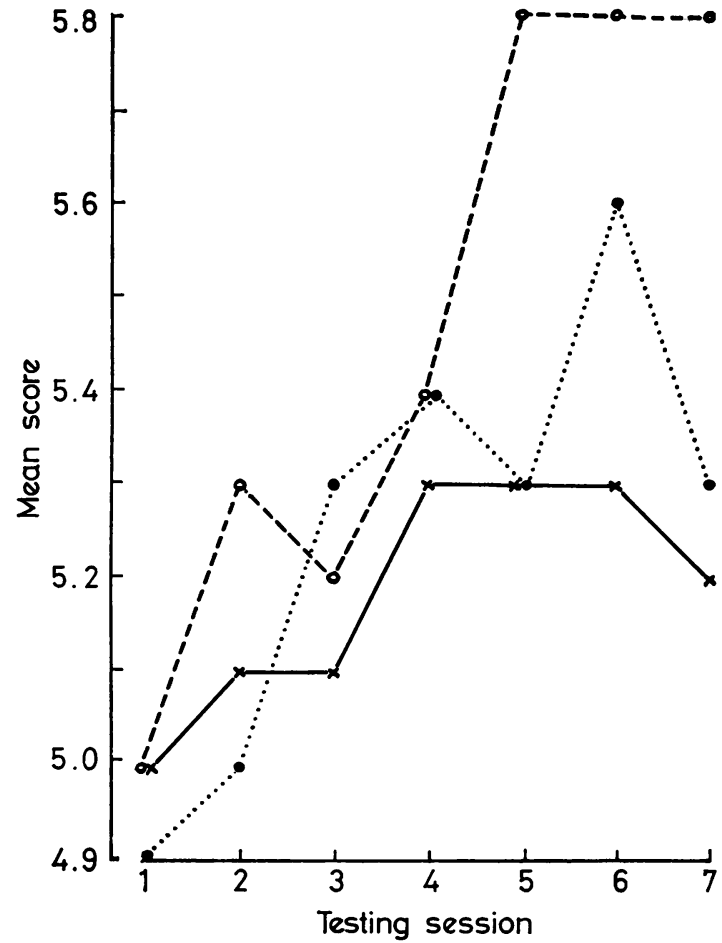

FIG. 2. Mean Wechsler Memory Scale Form 1, Part 1, score for treatment groups. $\mathbf{0}----\mathbf{0}=$ Unilateral non-dominant. $\times \longrightarrow \times$ Bilateral. $\bigcirc \ldots$. $=$ Unilateral dominant.

scores of all three groups were made after the sixth ECT using the Mann-Whitney $U$ Test. There were no significant differences between the treatment groups on the DI after the standard number of treatments (Table 5). No differences were found on PDS between the three groups after six ECTs (reactives and endogenous combined).

ii. The hypothesis that extra treatments would be required by both unilateral groups in order to obtain the same degree of improvement in depression is not entirely confirmed statistically. When both unilateral groups after the eighth ECT were compared separately with the bilateral groups after the sixth ECT, it was found that the unilateral dominant group only was significantly more depressed on the DI than the bilaterals (for combined reactive and endogenous depressives $P<.05$ and for the endogenous group in separate analysis $P<\cdot 005)$. These probability levels would suggest that most of the overall effect was attributable to the endogenous group. The unilateral non-dominant group was not significantly different from the bilateral.

The finding that unilateral dominant ECT is not so effective in relieving depression is highlighted by Fig. 4 . Unilateral non-dominant ECT is as beneficial as bilateral, although improvement may not be quite so rapid. 


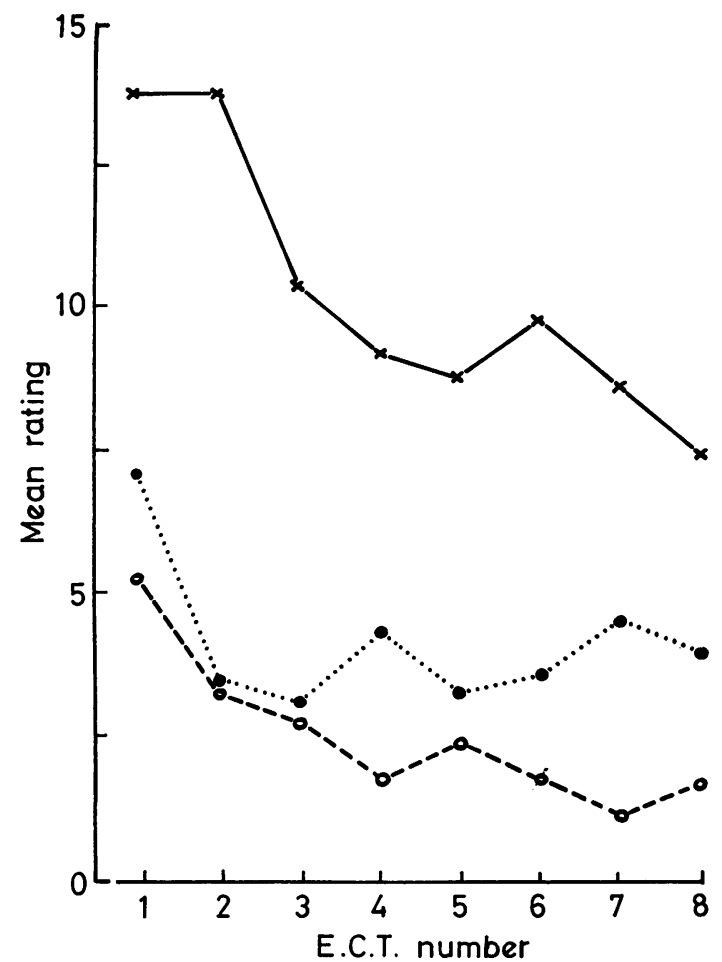

FIG. 3. Mean confusion rating for treatment groups. $\mathbf{0}---\mathbf{0}=$ Unilateral non-dominant. $\times-\times$ = Bilateral. ..... = Unilateral dominant.

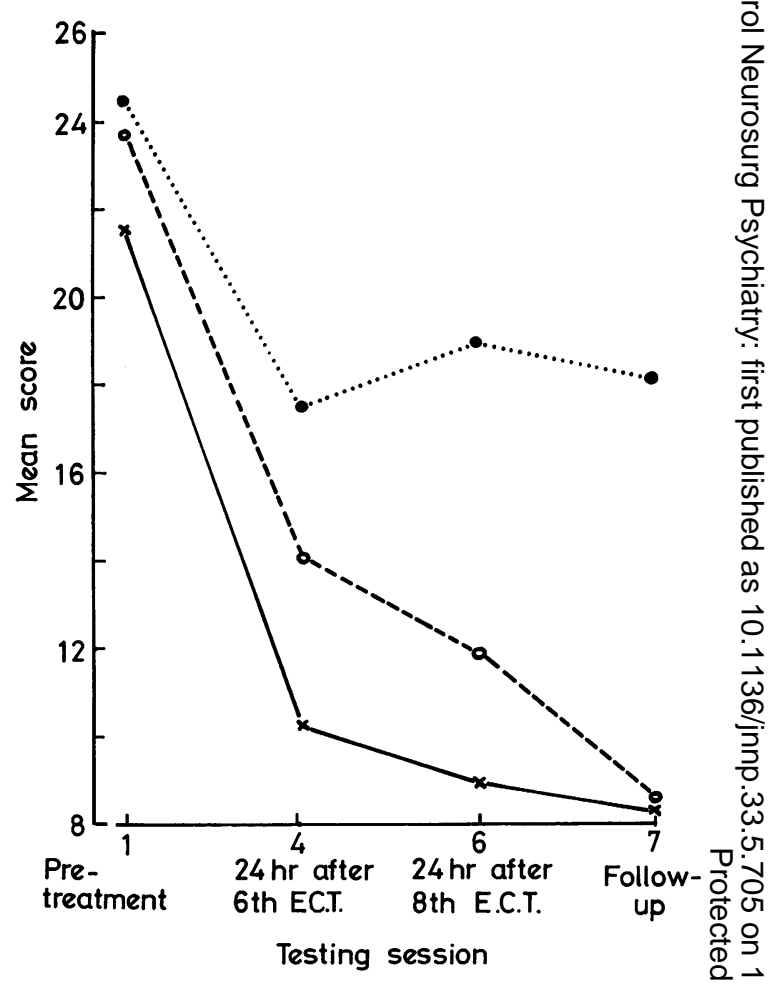

FIG. 4. Mean Beck Depression Inventory scores for treatment groups. $\mathbf{0}---0=$ Unilateral non-domi- $\bigcirc$

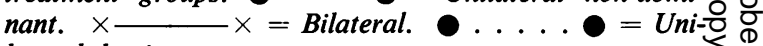
lateral dominant.

TABLE 4

SIGNIFICANCE OF DIFFERENCES BETWEEN TREATMENT GROUPS ON CONFUSION RATINGS AND QUESTIONS

\begin{tabular}{|c|c|c|c|c|c|c|c|c|}
\hline $\operatorname{ECT}\left(n c_{\bullet}\right)$ & 1 & 2 & 3 & 4 & 5 & 6 & 7 & 8 \\
\hline $\begin{array}{l}\text { Reactive depressives } \\
\text { Endogenous depressives } \\
\mathbf{R} \text { and } \mathbf{E} \text { combined }\end{array}$ & $\begin{array}{c}P=.02 \\
\text { N.S. } \\
P=.01\end{array}$ & $\begin{array}{l}P=\cdot 01 \\
P=.01 \\
P=.001\end{array}$ & $\begin{array}{c}P=.01 \\
\text { N.S. } \\
P=\cdot 01\end{array}$ & $\begin{array}{c}P=\cdot 02 \\
\text { N.S. } \\
P=\cdot 01\end{array}$ & $\begin{array}{c}P=\cdot 01 \\
\text { N.S. } \\
P=\cdot 02\end{array}$ & $\begin{array}{c}P=\cdot 01 \\
\text { N.S. } \\
P=\cdot 01\end{array}$ & $\begin{array}{c}P=\cdot 01 \\
\text { N.S. } \\
P=\cdot 001\end{array}$ & $\begin{array}{c}P=.01 \\
\text { N.S. } \\
P=.01\end{array}$ \\
\hline
\end{tabular}

TABLE 5

SIGNIFICANCE OF DIFFERENCES BETWEEN TREATMENT GROUPS ON DEPRESSION INVENTORY

\begin{tabular}{|c|c|c|c|c|}
\hline & Pre-treatment & $\begin{array}{r}24 \mathrm{hr} \text { after } \\
6 \text { th } \mathrm{ECT}\end{array}$ & $\begin{array}{c}24 \text { hr after } \\
\text { 8th ECT }\end{array}$ & Follow-up \\
\hline $\begin{array}{l}\text { Reactive depressives } \\
\text { Endogenous depressives } \\
\text { Combined } \mathbf{R} \text { and } \mathbf{E}\end{array}$ & $\begin{array}{l}\text { N.S. } \\
\text { N.S. } \\
\text { N.S. }\end{array}$ & $\begin{array}{l}\text { N.S. } \\
\text { N.S. } \\
\text { N.S. }\end{array}$ & $\begin{array}{l}\text { N.S. } \\
P=\cdot 05 \\
P=\cdot 05\end{array}$ & $\begin{array}{c}\text { N.S. } \\
P=.02 \\
P=.05\end{array}$ \\
\hline
\end{tabular}


(This is, in fact, consistent with our hypothesis.) The differences which were found on the DI were also borne out on the PDS.

The unilateral dominant group was also found to be more depressed (DI) than the other two groups both after the final ECT and at follow-up. From separate analysis this difference is again seen largely in the endogenous sample.

iii. The hypothesis that for all treatment groups the amount of immediate confusion following each treatment would be related to the degree of improvement in depression was rejected. The degree of improvement on the Depression Inventory was taken as the difference between the score on the initial assessment and that on follow-up assessment expressed as a ratio of the initial score. There were no significant correlations for combined endogenous and reactive groups (Spearman rho $=+\cdot 03$ ), nor within each depressive group separately.

\section{HYPOTHESIS III}

DIFFERENCES IN MEMORY IMPAIRMENT AND CONFUSION BETWEEN DIAGNOSTIC GROUPS (REACTIVE AND ENDOGENOUS DEPRESSIVES) This section of the results concerns the differences between the two kinds of depressives within the treatment groups, and thus led to the second stage of the statistical analysis. The Mann-Whitney $U$ test was used to assess the differences between the two groups (endogenous and reactive) for each test and each trial.

Verbal memory The hypothesis that the reactives would not differ from the endogenous depressives in terms of memory impairment was not entirely confirmed. On unilateral non-dominant ECT the reactives performed significantly better than the endogenous on the MWLT $(P<\cdot 05)$ and the Digit Span $(P<\cdot 05)$ after the sixth ECT. At the follow-up unilateral non-dominant reactives were also significantly better on the MWLT than the endogenous $(P<\cdot 02)$.

Visual memory One significant difference emerged in favour of reactives, on unilateral non-dominant ECT their performance on the MFD one hour after the sixth ECT was again superior to that of the endogenous group $(P<\cdot 05)$. For those on the other two treatments there appeared to be no visual or verbal memory differences between the endogenous and reactive groups.

Confusion and restlessness The two kinds of depressives did not differ significantly in terms of confusion on any of the three treatments, with one exception, the reactives were less confused than the endogenous on bilateral ECT after the seventh ECT $(P<\cdot 01)$.

ii. DIFFERENCES IN DEPRESSION BETWEEN DIAGNOSTIC GROUPS REACTIVE AND ENDOGENOUS DEPRESSIVES The hypothesis that the endogenous depressives might respond better to ECT than the reactives was again not entirely borne out. At the end of the sixth and eighth ECTs there were no significant differences in depression scores
(DI) between the groups, whichever treatment they received. At the follow-up, however, the endogenous group was significantly less depressed (according to the DI) than the reactives if they had bilateral ECT $(P<\cdot 05)$ Fig. 5 confirms this finding; it also clearly shows a tendency for the endogenous bilateral group to be the least depressed following the sixth and subsequent ECTs.

The Psychotic Depression Scale scores did not show significant differences between the two groups at any stage of any of the treatments.

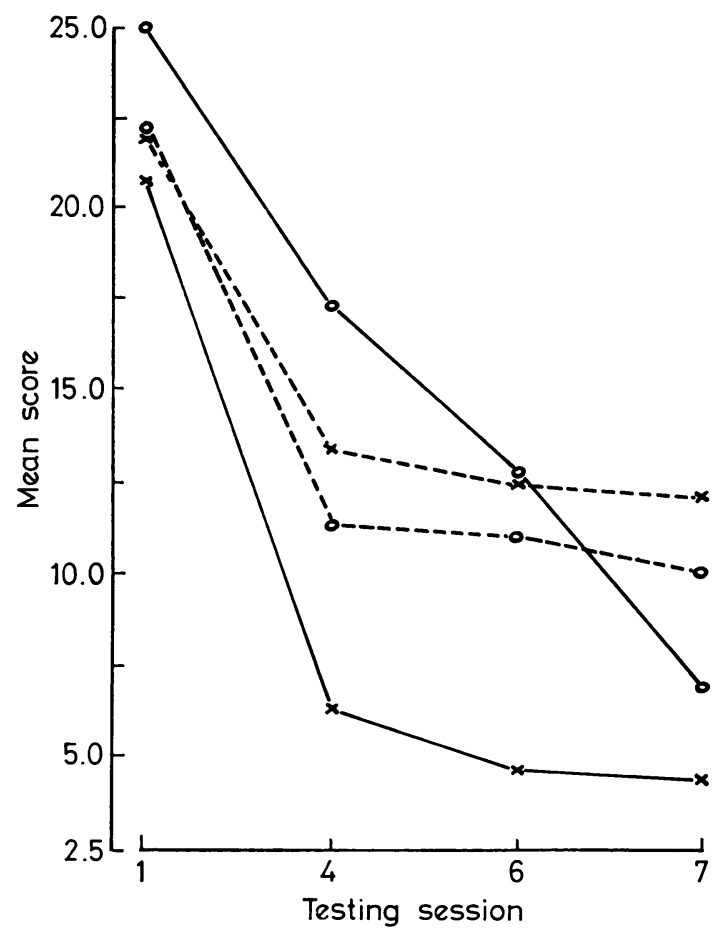

FIG. 5. Mean Beck Depression Inventory scores for unilateral non-dominant and bilateral groups (reactive and endogenous depressives shown separately). The unilateral dominant groups have been omitted to allow a clear comparison. $\mathbf{0}-\ldots$ reactive. Unilateral non-dominant endogenous. $\times----\times=$ Bilateral reactive.

$\times \longrightarrow=$ Bilateral endogenous.

\section{DISCUSSION}

1. There is a strong case for giving unilateral nondominant ECT to certain depressive patients. This form of treatment produces less immediate confusion and memory disturbance (particularly verbal memory) and yet seems ultimately to be as effective in relieving depression as bilateral ECT. The rate of improvement may not, however, be as rapid. In 
view of this finding it could be argued that treatment would be more effective if unilateral shocks were given at more frequent intervals. These observations apply more to the reactive than the endogenous depressives.

2. There are some indications that endogenous depressives might benefit more from bilateral ECT and that the penalty of greater symptomatic relief is relatively more confusion at time of treatment. However, taking all the depressives together, there was no relationship between amount of confusion and symptomatic relief.

3. The comparatively poor response of patients on unilateral dominant ECT emphasizes the importance (a) of foregoing ECT perhaps even in cases where damage of the non-dominant hemisphere would perhaps indicate unilateral dominant ECT, and (b) of confirming the dominance of the patient before undertaking unilateral non-dominant ECT. If the shock is mistakenly applied to the dominant hemisphere, the same degree of improvement is unlikely to be achieved.

When there is doubt about cerebral dominancefor example, in patients who are ambidextrous and possibly those who are left-handed-there is a case for administering bilateral ECT.

Halliday et al. (1968) have pointed out that there is some evidence for asymmetry in the cerebral mechanisms subserving affect, and quote Terzian and Cecotto (1959) who found that depression followed an injection of amylobarbitone into the carotid artery on the dominant side, while euphoria was produced by injection on the opposite side. This might partly, if not wholly, explain the fact that unilateral dominant ECT is not so effective in relieving depression.

This investigation confirms the earlier findings that unilateral ECT is an effective treatment with fewer side-effects, such as memory impairment. It appears that the treatment might be of particular value for those who earn their living by relying upon memory and other cognitive functions or in the elderly where the bilateral method may cause real organic confusion with marked intellectual disturbance and memory impairment, which is not always temporary.

While bilateral ECT appears of slightly greater value in patients with severe endogenous depression, it is worth varying the mode of administrationthat is, giving some bilateral treatments and the remainder unilateral, to these patients, thus attempting to reduce memory loss without losing therapeutic benefit.

The technique of administering unilateral ECT is no more difficult than giving bilateral treatment. There is also the likelihood of being able to adminis- ter treatment more frequently and at the same time achieve equal benefit without unreasonable side effects. This has the advantage of reducing duration of stay for in-patients.

The greater ease of management in the posttreatment phase of unilateral ECT for out-patients has marked advantages. Quicker recovery and fewer side-effects reduce the burden of nursing care, making it possible for patients to return to their? homes much earlier than is otherwise possible and to conduct their affairs normally.

We are very grateful to Siemens who lent the Convulsator 622 , and also the nursing staff who collaborated in the treatment and assessments.

\section{REFERENCES}

Archibald, Y. M., and Wepman, J. M. (1968). Language disturbance and nonverbal cognitive performance in eight patients following injury to the right hemisphere. Brain, 91, 117-130.

Archibald, Y. M., Wepman, J. M., and Jones, L. V. (1967). Performance on nonverbal cognitive tests following $\omega$ unilateral cortical injury to the right and left $v$ hemisphere. J. nerv. ment. Dis., 145, 25-36.

Beck, A. T., Ward, C. H., Mendelson, M., Mock, J., and ভ Erbaugh, J. (1961). An inventory for measuring depression. Arch. gen. Psychiat., 4, 561-571.

Cannicott, S. M. (1962). Unilateral electro-convulsive therap Postgrad. med. J., 38, 451-459.

Carney, M. W. P., Roth, M., and Garside, R. F. (196\$ The diagnosis of depressive syndromes and the pre diction of E.C.T. response. Brit. J. Psychiat., 11兵 659-674.

Dick, D. H. (1967). Personal communication.

Foulds, G. A. (1960). Psychotic depression and age. J. ment. Sci., 106, 1394-1397.

Gottlieb, G., and Wilson, I. (1965). Cerebral dominance: Temporary disruption of verbal memory by unilateral electroconvulsive shock treatment. $J$. comp. Physiol. Psychol., 60, 368-372.

Halliday, A. M., Davison, K., Browne, M. W., and Kreeger, L. C. (1968). A comparison of the effects on depression and memory of bilateral E.C.T. and unilateral $\overrightarrow{\bar{O}}$ E.C.T. to the dominant and non-dominant hemispheres. Brit. J. Psychiat., 114, 997-1012.

Hamilton, M. (1967). Development of a rating scale for primary depressive illness. Brit. J. soc. clin. Psychol., 6, 278-296.

Impastato, D. J., and Karliner, W. (1966). Control of memory impairment in EST by unilateral stimulation of the non-dominant hemisphere. Dis. nerv. Syst., 27, 183188.

Kendell, R. E. (1968). The Classification of Depressive? Illness. (Maudsley Monograph No. 18.). Oxford University Press: London.

Lancaster, N. P., Steinert, R. R., and Frost, I. (1958). 을 Unilateral electro-convulsive therapy. J. ment. Sci., D 104, 221-227.

Levy, R. (1968). The clinical evaluation of unilateral electroconvulsive therapy. Brit. J. Psychiat., 114, 459-463. N

Martin, W. L., Ford, H. F., McDonald, E. C., and Towler, M. L. (1965). Clinical evaluation of unilateral EST. N Amer. J. Psychiat., 121, 1087-1090. 
Mayer-Gross, W., Slater, E., and Roth, M. (1969). Clinical Psychiatry. 3rd edn., Baillière, Tindall and Cassell: London.

McAndrew, J., Berkey, B., and Matthews, C. (1967). The effects of dominant and non-dominant unilateral E.C.T. as compared to bilateral E.C.T. Amer. J. Psychiat., 124, 483-490.

Metcalfe, Maryse, and Goldman, Ellen (1965). Validation of an inventory for measuring depression. Brit. $J$. Psychiat., 111, 240-242.

Miller, E. (1967). Psychological theories of E.C.T.: A review, Brit. J. Psychiat., 113, 301-311.

Pacella, B. L., and Impastato, D. J. (1954). Focal stimulation therapy. Amer. J. Psychiat., 110, 576-578.
Siegel, S. (1956). Nonparametric Statistics: For the Behavioral Sciences. McGraw-Hill Book Co.: New York.

Terzian, H., and Cecotto, C. (1959). Su un nuovo metodo per la determinazione e lo studio della dominanza emisferica. G. Psichat. Neuropat., 57, 1-35.

Williams, Moyra (1965). Mental Testing in Clinical Practice, p. 86, Pergamon Press: Oxford.

Zamora, E. N., and Kaelbling, R. (1965). Memory and electroconvulsive therapy. Amer. J. Psychiat., 122, 546-554.

Zinkin, Sheila, and Birtchnell, J. (1968). Unilateral electroconvulsive therapy. Its effect on memory and its therapeutic efficacy. Brit. J. Psychiat., 114, 973-988.

\section{The August 1970 Issue}

\section{THE AUGUST 1970 ISSUE CONTAINS THE FOLLOWING PAPERS}

Cryptococcosis of the central nervous system: epidemiological, clinical, and therapeutic features V. E. EDWARDS, J. M. SUTHERLAND, and J. H. TYRER

Experimental cerebral schistosomiasis japonica in primates JOHN A. JANE, KENNETH S. WARREN, and STANLEY VAN DEN NOORT

Myasthenia gravis in the dog D. C. FRASER, A. C. PALMER, J. E. B. SENIOR, J. D. PARKES, and M. F. T. YEALLAND

Stimulus intensity and site of excitation in human median nerve sensory fibres W. C. WIEDERHOLT

Electrophysiological studies in diabetic neuropathy ALBERT LAMONTAGNE and FRITZ BUCHTHAL

Atypical deep peroneal neuropathy L. GUTMANN

On the problem of the pathology of spasmodic torticollis in man EDWARD TARLOV

A new agent for the control of spasticity RICHARD F. JONES, DAVID BURKE, J. E. MAROSSZEKY, and J. D. GILLIES

Primary non-skeletal intracranial cartilaginous neoplasms: report of a chondroma and a mesenchymal chondrosarcoma WILLIAM Q. WU and ANGELO LAPI

Is reading epilepsy inherited? A. J. ROWAN, K. W. G. HEATHFIELD, and D. F. SCOTT

Gelastic epilepsy JOHN GUMPERT, PHIROZE HANSOTIA, and ADRIAN UPTON

Iatrogenic lumbar meningocoele ITALO RINALDI and THOMAS O. HODGES
Occult intrasacral meningocoele ROMA A. JOSEPH and THOMAS MCKENZIE

Cerebral cortex perfusion rates in dementia M. D. O'BRIEN and B. L. MALLETT

The distribution of plasma phenytoin levels in epileptic patients P. T. LASCELlES, R. S. KOCEN, and E. H. REYNOLDS

Fatty acid composition of phospholipids from platelets and erythrocytes in multiple sclerosis s. GUL, A. D. SMITH, R. H. S. THOMPSON, H. PAYLING WRIGHT, and $\mathrm{K}$. J. ZILKHA

Failure of pyridoxine to reduce drug-induced dyskinesias GEORGE E. CRANE, IBRAHIM S. TUREK, and ALBERT A. KURLAND

Neurosurgery in cerebral palsy L. V. LAITINEN

Observations on muscle pain in man, with particular reference to pain during needle electromyography J. C. MEADOWS

Persistent proatlantal artery N. A. HUTCHINSON and J. D. R. MILLER

Treatment of paroxysmal disorders in multiple sclerosis with carbamazepine (Tegretol) MICIIAEL L. E. ESPIR and PAUL MILLAC

Autonomic failure in hydrencephaly OTTO APPENZELLER, RUSSELL SNYDER, and MARIO KORNFELD

Pancreatic function in amyotrophic lateral sclerosis ROBERT A. UTTERBACK, ALVIN J. CUMMINS, CHARLES A. CAPE, and JULIO GOLDENBERG

Book reviews

Copies are still available from the PUBLISHING MANAGER, BRITISH MEDICAL ASSOCIATION, TAVISTOCK SQUARE, LONDON, WC1H 9JR, price $21 s$. 